\title{
Strategies to improve the understanding of long-term renal consequences after neonatal acute kidney injury
}

\author{
David J. Askenazi ', Catherine Morgan², Stuart L. Goldstein ${ }^{3}$, David T. Selewski ${ }^{4}$ Marva M. Moxey-Mims ${ }^{5}$, Paul L. Kimmel' \\ Robert A. Star ${ }^{5}$, Rosemary Higgins ${ }^{6}$ and Matthew Laughon ${ }^{7}$
}

\section{INTRODUCTION}

Advances in neonatal care have improved survival rates in critically ill neonates (1). Now the focus is turning toward reducing the long-term morbidities. Premature infants and critically ill neonates are at risk for chronic kidney disease (CKD), yet the exact pathophysiology, incidence, risk factors, and outcomes are not yet known. Acute kidney injury (AKI) has emerged as a risk factor for future CKD in both pediatric $(2,3)$ and adult observational studies $(4,5)$. Animal models have begun to identify the pathophysiologic mechanisms that lead to the development of CKD after episodes of AKI (5-8). While there has been significant progress in studying the short-term implications of AKI in neonates, numerous critical gaps in our understanding of the epidemiology of neonatal AKI and the future development of CKD remain. There are no clear evidence-based guidelines for the optimal follow-up of infants at risk for development of CKD, nor are there specific interventions designed to improve outcomes. As more critically ill premature infants and neonates with AKI live into adulthood, the impact that neonatal health has on CKD may potentially pose a tremendous health and economic burden.

The neonatal AKI workshop sponsored by the National Institutes of Health on 9 April 2013 provided a platform for pediatricians, nephrologists, neonatologists, and National Institute of Diabetes and Digestive and Kidney Diseases leadership to discuss optimal ways to bridge knowledge gaps. The ultimate goal was to develop a new framework to address important questions about how kidney health in the neonatal intensive care unit may have short- and long-term consequences.

A separate white paper will discuss the challenges to defining neonatal AKI. This summary is based on workshop discussions focused on the feasibility of conducting large prospective multicenter studies to determine the long-term renal effects of neonatal AKI. The following themes will be addressed in this report: (i) statement of the problem, (ii) key elements needed to conduct a long-term follow-up study, (iii) challenges, and (iv) opportunities.

\section{STATEMENT OF THE PROBLEM}

There are several reasons why at-risk infants may develop CKD. Contributing factors may include incomplete nephrogenesis, maternal drug exposure, intrauterine growth retardation, prematurity, and AKI during the first months of life. In order for us to understand how neonatal AKI impacts long-term renal outcomes, close evaluation of other potential contributors to CKD needs to be understood and accounted in studies of the AKI to CKD paradigm in neonates.

Nephrogenesis begins at the fifth week of gestation and continues until $34 \mathrm{wk}$ post-conception (9). Infants born at $<34$ wk of gestational age may have a paucity of nephrons (10). If nephrogenesis is continuing after birth, the extrauterine environment may not allow for proper glomerular development (11). Thus, premature infants $<34 \mathrm{wk}$ are at risk for CKD due to lesser number of nephron. Intrauterine growth retardation affects gene expression and nephron endowment, and filtration surface area $(12,13)$ are decreased in animals with intrauterine growth retardation. The timing of the growth restriction may be a key element affecting renal development.

Premature and low-birth-weight (LBW) infants are at risk for the development of CKD. Prematurity is $<37$ completed weeks post-conception. Late preterm is $34-36 \mathrm{wk}$, which accounts for $\sim 75 \%$ of the premature infants in the United States (14). Most observational studies have focused on infants with LBW $(<2,500 \mathrm{~g})$ when describing the long-term implications of prematurity. A recent meta-analysis of observational studies demonstrated that LBW infants have approximately twice the risk of albuminuria, low estimated glomerular filtration rate, and end-stage renal disease compared with their term peers (15). An analysis of the National Institutes of Health-sponsored Chronic Kidney Disease in Children study showed that $17 \%$ of the cohort had a history of LBW and 13\% were premature (16). While these studies illuminate the future risk of CKD in premature infants, they likely represent only the tip of the iceberg, as the smallest and most vulnerable infants were not included in these studies. Since the introduction of surfactant in 1987, survival of extremely-low-birth-weight infants $(<1,000 \mathrm{~g})$ is

\footnotetext{
'Department of Pediatrics, University of Alabama at Birmingham, Birmingham, Alabama; ${ }^{2}$ Department of Pediatrics, University of Alberta, Edmonton, Alberta, Canada; ${ }^{3}$ Department of Pediatrics, Cincinnati Children's Hospital and Medical Center, Cincinnati, Ohio; ${ }^{4}$ Department of Pediatrics, University of Michigan, Ann Arbor, Michigan; ${ }^{5}$ Division of Kidney, Urology and Hematology, National Institute of Diabetes and Digestive and Kidney Diseases, National Institutes of Health, Bethesda, Maryland; ${ }^{6}$ Pregnancy and Perinatology Branch, Eunice Kennedy Shriver National Institute of Child Health and Human Development, National Institutes of Health, Bethesda, Maryland; ${ }^{7}$ Department of Pediatrics, University of North Carolina at Chapel Hill, Chapel Hill, North Carolina. Correspondence: David Askenazi (daskenazi@peds.uab.edu)

Received 1 May 2015; accepted 28 August 2015; advance online publication 16 December 2015. doi:10.1038/pr.2015.241
} 
now commonplace across the United States. It is very likely that long-term studies of these extremely premature infants will yield even higher rates of CKD.

AKI is a risk factor for the development of CKD (5). Research over the past decade has provided substantial data showing that AKI leads to CKD (2-8). Although the exact mechanisms underlying the progression from AKI to CKD continue to be explored, endothelial damage may play a critical role in outcomes, leading to nephron drop-out, interstitial fibrosis, and, ultimately, CKD (5-17). A full review of the data on the link between AKI and CKD in animals and adults is beyond the scope of this article but has recently been performed (5).

AKI is common in critically ill neonates and is associated with adverse short-term outcomes. Premature infants are hospitalized for extended periods following birth, usually to around the time of the expected due date. During their hospitalization, premature infants are exposed to multiple risk factors for AKI, including hypotension, nephrotoxic drugs (such as nonsteroidal anti-inflammatory drugs and aminoglycoside antibiotics), and infections (e.g., sepsis, urinary tract infections). The risk for AKI in premature infants is highest in those with lower gestational age. The incidence of AKI in this group is estimated to be between 12 and $40 \%$ (18-20). Other neonatal cohorts at high risk of developing AKI include those with congenital heart disease who receive cardiopulmonary bypass, near-term/term sick infants requiring intensive care, neonates with hypoxic-ischemic encephalopathy, necrotizing enterocolitis, sepsis, and neonates who receive extra-corporeal membrane oxygenation. Table 1 lists the incidence, risk factors, and outcomes of AKI described in recent cohort studies.

AKI during ongoing nephrogenesis may play an important role in limiting glomerular endowment and/or exacerbating abnormal development. Carefully performed studies are needed to better inform families, neonatologists, pediatric nephrologists, pediatricians, and internists about the longterm risk of $\mathrm{AKI}$ for $\mathrm{CKD}$ in this vulnerable population.

\section{KEY ELEMENTS NEEDED TO CONDUCT A LONG-TERM FOLLOW-UP STUDY \\ Population}

Defining the population is arguably the most important decision in developing a long-term prospective cohort study. There are advantages and disadvantages in following an entire cohort of hospital survivors with and without AKI, compared with following only neonates with AKI. A cohort of LBW infants (birth weight $<2,500 \mathrm{~g}$ ) with careful records of neonatal course, interventions, laboratory findings, and clinical outcomes will be critical to assigning AKI phenotypes, allowing comparison of patients with and without AKI. Collection of patient demographics and characteristics (such as degree of prematurity and intrauterine growth) will be necessary. Evaluation of the risk factors for, etiology of, severity of, and duration of AKI will help elucidate the factors that potentially lead to CKD. This approach would ideally use similar infants without AKI as controls. This type of study could be integrated within already existing infrastructures (i.e., neonatal follow-up clinics).
Another approach would be to follow neonates with known AKI, regardless of the underlying conditions or cause of AKI. Such patients could be compared with a normal-term cohort. An advantage of this approach is that a variety of etiologies of neonatal AKI could be included in a single study, although a heterogeneous population could confound the study design and interpretation of results. Studying high-risk neonates may provide the most important information regarding long-term health outcomes and be economical, since not many infants without AKI would need to be followed. A disadvantage is that a true comparison group would not be included (e.g., infants with cardiac lesions without AKI), and thus the long-term outcomes of AKI could be compared only across different types or degrees of AKI.

Whether a specific neonatal population is followed, or whether neonatal groups with AKI of different etiologies are followed, appropriate comparison groups will be needed. There have been a handful of older studies demonstrating possible relationships between neonatal AKI and longer-term outcomes (21). Since control populations were lacking, conclusions regarding incidence, risk factors, and relative risk could not be made.

It seems appropriate to exclude neonates with cardiac transplantation, known severe congenital renal anomalies, inborn errors of metabolism, lethal chromosomal abnormalities, or those in whom survival was not anticipated from any cohort assembled to assess long-term complications of AKI.

\section{Sample Size}

A follow-up study of CKD in at-risk infants will need a large sample size. A few previous studies were clearly underpowered. Morgan et al. (22) evaluated 264 neonates having complex cardiac surgery and demonstrated differences in growth and 2-y health utilization outcomes between neonates with and without AKI. The study, however, was not powered to elucidate differences in mortality or CKD. Although precise sample size calculations are difficult to perform without a specific study design in mind, the group estimated that it may take 1,000-1,500 hospital survivors to provide sufficient power. If each center enrolls an average of 40 patients per year ( 80 over $2 \mathrm{y}$ ), it would take $\sim 12-18$ centers to enroll the needed number of participants for such a study.

\section{Exposure Variables}

Besides gathering maternal and infant demographic and clinical information, clinical interventions, and comorbidities, it will be critical to ascertain whether AKI occurred during the neonatal course. A minimum number of serum creatinine concentration measurements will be needed to minimize ascertainment bias. Without serum creatinine values, one would not know if AKI occurred based on current definitions. Therefore, serum creatinine would need to be measured at least several times per week, if not daily.

Classification of the severity of AKI into stages according to empiric neonatal AKI definitions (stage $0,1,2$, and 3 corresponding to no, mild, moderate, and severe AKI) may be beneficial. Evaluation of both kidney damage (measured by urine biomarkers) as well as changes in kidney function (measured 
Table 1. Studies on neonatal acute kidney injury

\begin{tabular}{|c|c|c|c|c|c|}
\hline Study & Population & Definition & $\begin{array}{l}\text { AKI } \\
\text { incidence }\end{array}$ & AKI risk factors & Conclusions \\
\hline $\begin{array}{l}\text { Askenazi } \\
\text { et al. (34) }\end{array}$ & $\begin{array}{l}\text { Very-low-birth-weight } \\
\text { infants }(N=195)\end{array}$ & $\begin{array}{l}\text { AKIN } \\
\text { criteria }\end{array}$ & $\begin{array}{l}\text { Matched } \\
\text { case-control } \\
\text { study }\end{array}$ & $\begin{array}{l}\text { Receive chest compressions, receive } \\
\text { cardiac drugs, intraventricular hemorrhage }\end{array}$ & $\begin{array}{l}\text { AKI is associated with increased } \\
\text { mortality after adjustment for } \\
\text { confounders }\end{array}$ \\
\hline $\begin{array}{l}\text { Gadepalli } \\
\text { et al. (35) }\end{array}$ & $\begin{array}{l}\text { Congenital diaphragmatic } \\
\text { hernia on extracorporeal } \\
\text { membrane oxygenation } \\
(N=68)\end{array}$ & $\begin{array}{l}\text { RIFLE } \\
\text { criteria }\end{array}$ & $71 \%$ & $\begin{array}{l}\text { Lower 5-min Apgar score, AKI correlated } \\
\text { with left-sided congenital diaphragmatic } \\
\text { hernia }\end{array}$ & $\begin{array}{l}\text { Increased risk of mortality at highest } \\
\text { level of AKI (failure) }\end{array}$ \\
\hline $\begin{array}{l}\text { Kaur et al. } \\
2011(36)\end{array}$ & Perinatal asphyxia $(N=36)$ & $\begin{array}{l}\text { AKIN } \\
\text { criteria }\end{array}$ & $41.7 \%$ & Severe asphyxia (Apgar $<3$ at $1 \mathrm{~min}$ ) & $\begin{array}{l}\text { Modern definitions (AKIN) capture } \\
\text { AKI previously missed by previous } \\
\text { standard of } \mathrm{SCr}>1.5 \mathrm{mg} / \mathrm{dl}\end{array}$ \\
\hline $\begin{array}{l}\text { Koralkar } \\
\text { et al. (19) }\end{array}$ & $\begin{array}{l}\text { Very-low-birth-weight } \\
\text { infants }(N=229)\end{array}$ & $\begin{array}{l}\text { Neonatal } \\
\text { KDIGO } \\
\text { criteria }\end{array}$ & $18 \%$ & $\begin{array}{l}\text { Lower birth weight, lower gestational } \\
\text { age, lower Apgar scores, UAC, mechanical } \\
\text { ventilation, inotrope support }\end{array}$ & $\begin{array}{l}\text { AKI associated with increased } \\
\text { mortality independent of severity of } \\
\text { illness }\end{array}$ \\
\hline $\begin{array}{l}\text { Selewski } \\
\text { et al. (39) }\end{array}$ & Perinatal asphyxia $(N=96)$ & $\begin{array}{l}\text { Neonatal } \\
\text { KDIGO } \\
\text { criteria }\end{array}$ & $38 \%$ & $\begin{array}{l}\text { Asystole at the time of birth, clinical } \\
\text { seizures before cooling, persistent } \\
\text { pulmonary hypertension, elevated } \\
\text { gentamicin or vancomycin levels, pressor } \\
\text { support, transfusions }\end{array}$ & $\begin{array}{l}\text { AKI predicted prolonged mechanical } \\
\text { ventilation, increased length of stay, } \\
\text { and abnormal brain MRI findings at } \\
7-10 \mathrm{~d} \text { of life }\end{array}$ \\
\hline $\begin{array}{l}\text { Zwiers } \\
\text { et al. (40) }\end{array}$ & $\begin{array}{l}\text { Extracorporeal membrane } \\
\text { oxygenation }<28 d \\
(N=242)\end{array}$ & $\begin{array}{l}\text { RIFLE } \\
\text { criteria }\end{array}$ & $64 \%$ & $\begin{array}{l}\text { Younger age at initiation, lack of pre-ECMO } \\
\text { inhaled nitric oxide }\end{array}$ & $\begin{array}{l}\text { Increased risk of mortality at highest } \\
\text { level of AKI (failure) }\end{array}$ \\
\hline $\begin{array}{l}\text { Rhone } \\
\text { et al. (41) }\end{array}$ & $\begin{array}{l}\text { Very-low-birth-weight } \\
\text { infants }(N=107)\end{array}$ & $\begin{array}{l}\text { Neonatal } \\
\text { KDIGO } \\
\text { criteria }\end{array}$ & $26.2 \%$ & Nephrotoxic exposure & $\begin{array}{l}\text { AKl associated with nephrotoxic } \\
\text { medication exposure }\end{array}$ \\
\hline
\end{tabular}

AKI, acute kidney injury; AKIN, acute kidney injury network; CPB, cardiopulmonary bypass; CRIB, clinical risk index for babies; ECMO, extra-corporeal membrane oxygenation; KDIGO, kidney disease improving global outcomes; MRI, magnetic resonance imaging; RIFLE, risk, injury, failure, loss, end-stage criteria; SCr, serum creatinine; UAC, umbilical artery catheter.

by serum creatinine and/or urine output) may help elucidate which infants are at risk for long-term kidney damage. Evaluation of similar newborns without AKI will be necessary to make proper conclusions.

\section{Outcome Measurements}

The most important outcome measurements are glomerular filtration rate (GFR) and blood pressure. Both are meaningful measurements to track because early identification of abnormal GFR and hypertension are critical to reduction of the morbidity and mortality associated with these conditions. Furthermore, these are areas that may allow for intervention to improve long-term outcomes, such as with antihypertensive medications or with inhibitors of the renin-angiotensinaldosterone system. These diminished GFR and increased blood pressure could serve as targets for evidence-based monitoring of high-risk infants throughout childhood. As the renin-angiotensin-aldosterone system is involved in normal nephrogenesis and interventions from maternal medications that block this system have been shown to cause congenital renal abnormalities, a careful evaluation to determine whether angiotensin receptor blocker and/or angiotensinconverting enzyme inhibitors are beneficial will be needed prior to widespread use.

Secondary outcome measurements could include a variety of tests that would augment the knowledge regarding AKI and the transition from AKI to CKD. These include microalbuminuria determined on a first morning urine sample, a renal ultrasound, evaluation of tubular function (ability of tubules to properly reabsorb sodium, phosphorus, magnesium, calcium, potassium, and water), growth and growth velocity, and neurodevelopmental assessments (as appropriate depending 
on the age of the infant or child). Table 2 provides examples of the types of tests and potential schedule of a long-term follow-up study.

Exploratory evaluations could include tests that show significant promise. New imaging and biomarker discoveries are very promising methods to track renal damage and injury progression and could serve as potential surrogate outcomes of CKD. These have been identified in research settings in unique populations but have not been explored in young children. For example, resolution of renal magnetic resonance imaging is so precise that measurement of nephron number is possible (23).

Although the field of CKD biomarkers is in its infancy, we anticipate that several biomarkers could be used to assess and track disease progression and response to therapy in pediatric patients with neonatal AKI and CKD $(24,25)$. Hair and nail samples can be useful to assess heavy metal exposure and other potential causes of CKD. Collection of DNA may help elucidate genetic loci associated with CKD and its progression. Geospatial variables may help elucidate whether environmental/social factors affect CKD outcomes in this cohort. Urine and serum specimens should be biobanked for future research as the fields of proteomics and metabolomics develop. As such, any study that moves forward should have a biorepository as a key component (26).

The renal functional reserve test may be an excellent way to determine changes in renal function before changes in total nephron GFR occur. This test measures the differences in GFR before and after a stimulus designed to increase GFR. Those with renal reserve will increase GFR, while those without an increase are assumed to be functioning at maximal renal function due to single nephron hyperfiltration. Although these studies have been around available for more than for $30 \mathrm{y}(27)$, they are used infrequently, due to the time and effort required to conduct these tests. Simpler methods to assess renal functional reserve (such as measuring cystatin $\mathrm{C}$ before and after

Table 2. Example timeline of evaluation of outcomes for premature infants with AKI

\begin{tabular}{lcccccc}
\hline Test & Prior to & & & & & \\
hospital D/C & $6 \mathrm{mo}$ & $2 \mathrm{y}$ & $6 \mathrm{y}$ & $12 \mathrm{y}$ & $18 \mathrm{y}$ \\
\hline eGFR & $\mathrm{X}$ & $\mathrm{X}$ & $\mathrm{X}$ & $\mathrm{X}$ & $\mathrm{X}$ & $\mathrm{X}$ \\
lohexol GFR & - & - & - & $\mathrm{X}$ & $\mathrm{X}$ & $\mathrm{X}$ \\
Manual BP & $\mathrm{X}$ & $\mathrm{X}$ & $\mathrm{X}$ & $\mathrm{X}$ & $\mathrm{X}$ & $\mathrm{X}$ \\
ABPM & - & - & - & $\mathrm{X}$ & $\mathrm{X}$ & $\mathrm{X}$ \\
Urine ma/cr & $\mathrm{X}$ & $\mathrm{X}$ & $\mathrm{X}$ & $\mathrm{X}$ & $\mathrm{X}$ & $\mathrm{X}$ \\
RFR & - & - & $\mathrm{X}$ & - & - & $\mathrm{X}$ \\
Ultrasound & $\mathrm{X}$ & - & $\mathrm{X}$ & $\mathrm{X}$ & - & $\mathrm{X}$ \\
Assessment of & $\mathrm{X}$ & $\mathrm{X}$ & $\mathrm{X}$ & $\mathrm{X}$ & $\mathrm{X}$ & $\mathrm{X}$ \\
tubularfunction & & & & & & \\
DEXA scan & - & - & - & $\mathrm{X}$ & - & $\mathrm{X}$ \\
Growth and & $\mathrm{X}$ & $\mathrm{X}$ & $\mathrm{X}$ & $\mathrm{X}$ & $\mathrm{X}$ & $\mathrm{X}$ \\
development & & & & & & \\
\hline
\end{tabular}

ABPM, ambulatory blood pressure monitoring; BP, blood pressure; D/C, discharge; DEXA, dual-energy X-ray absorptiometry; eGFR, estimated glomerular filtration rate; MA/CR, microalbumin/creatinine; RFR, renal functional reserve. a protein load) and methods to provide a large protein load (such as ingestion of a beef hamburger or a protein shake) are currently being tested. The renal functional reserve may one day be an excellent method to assess single-nephron hyperfiltration early in life. The specific type of protein load used will need to be determined for different age ranges.

\section{Study Duration}

There was agreement that children should be followed serially, including an evaluation potentially until 17-18 y of age (a critical point in the transition of medical care). This would be very beneficial for the development of clear guidelines for evaluation and care in this at-risk population.

\section{CHALLENGES}

Few large, high-quality interventional or observational studies are conducted with children compared with adults. Performing clinical trials in children is challenging and substantially different than adult studies in terms of recruitment challenges, operational feasibility, and ethical considerations. Following infants through early childhood and school years can be difficult. Strategies to enhance adherence and retention (for example study visits could be organized to minimize disruption in parent employment, school attendance, and family routine) might play critical roles in enhancing the feasibility of longitudinal studies.

In addition, ethical issues in pediatric trial design need to be addressed to ensure that conduct of pediatric trials is safe and appropriate. For example, in pediatric studies, if a procedure does not provide any direct benefit, it must be classified as very low risk (28). Institutional review boards will not allow a study to be conducted unless such criteria are met. Thus, pediatric studies require expertise in pediatric clinical trial methodology, physiologic developmental issues, and assent and consent, as well as ethical issues (29). Despite these challenges, successful clinical research studies that follow infants for years after hospital discharge have been performed $(30,31)$. Such studies provide the necessary evidence-based information which serves to guide worldwide clinical practice of neonatal care.

Recruitment and retention for long-term studies into childhood is challenging and requires continuous, close contact with the infant's family and "buy-in" from the family into the proposed research. The relationship among the followup coordinator, social services, and the family is crucial to maintain a high longitudinal participation rate. Research networks such as the National Institute of Child Health and Human Development (NICHD) Neonatal Research Network (NRN) have consistently achieved a follow-up rate of $\geq 90 \%$ at $2 \mathrm{y}$ and beyond. It is critical that particular attention be given to specific populations in whom recruitment may be low and loss to follow-up may be high. One such group is neonates of low socioeconomic status. In accordance with institutional review board regulations, consideration should be given to ensure adequate representation of neonates from all socioeconomic strata. Referral patterns and center-specific recruitment and retention practices need to be considered. An effective 


\section{Special Article | Askenazietal.}

transition is necessary from the recruitment and early study period to long-term follow-up. This may involve or require a transition from neonatal specialists to nephrologists.

In addition to successful recruitment and retention, collection of consistent meaningful data across centers is critical. For example, education on the proper methods to measure blood pressure across sites will be critical. Ambulatory blood pressure monitoring, perhaps the gold-standard method to define hypertension, cannot be performed in children younger than 6 y (32). Blood collection and standardized procedures to accurately measure GFR are critical. Urine collection can be difficult in neonatal intensive care unit because many sick infants do not have bladder catheters placed. Urine in the outpatient setting can be collected using bags for urine collection. When possible, and at the appropriate ages, gold-standard measurements for the outcomes of interest should be employed. These include formal GFR measurements (such as iohexol) (33) and ambulatory blood pressure measurements (32). Albeit challenging, obtaining high-quality data will be critical to the study success.

\section{OPPORTUNITIES}

In discussing the feasibility of a long-term renal followup study, we considered successes of a number of neonatal research groups. Currently, several subsets of infants (premature, cardiopulmonary bypass, extra-corporeal membrane oxygenation, hypoxic-ischemic encephalopathy) at risk for $\mathrm{AKI}$ and $\mathrm{CKD}$ are registered in long-term follow-up clinics, as they are at risk for other negative health outcomes. The majority of follow-up clinics, however, do not consider the renal consequences of early life AKI and potential for CKD. These networks provide valuable insight into the feasibility and successful implementation of collaborative multicenter neonatal and pediatric studies within created infrastructures. Leveraging existing networks is a cost-effective way to study long-term renal outcomes in these cohorts. In addition, these networks provide cohort-specific collaborations and can help to disseminate study findings.

Research Networks in North America include the NICHD NRN, the Vermont Oxford Registry, the Canadian Neonatal Network, the Pediatrics Trial Network (PTN), and Pediatric Heart Network. Private corporations (for example Pediatrix) can track observational data in large cohorts. The NICHD NRN would more likely serve to answer important questions in the context of randomized clinical trials. Several of these research consortia are described below.

\section{The Eunice Kennedy Shriver NICHD NRN}

The NRN is designed to conduct high-quality trials to improve the health of infants. The NRN currently consists of 18 centers across the United States and includes a separate Data Coordinating Center (see below). One of the main features of the NRN is that it has an established follow-up program for participants through $2 \mathrm{y}$ of age, with retention consistently above $90 \%$. Occasionally, the NRN supports follow-up of individual trials (e.g., Whole Body Cooling, SUPPORT neuroimaging cohort) through early childhood (i.e., 6-7 y). A unique advantage of the NRN is that all examiners must be certified each year to ensure consistent evaluations.

\section{Pediatric Trials Network}

The PTN began in fall 2010 and is designed to conduct highquality pharmacokinetic and pharmacodynamic trials in children. The PTN will conduct up to 30 trials in children over the next $7 \mathrm{y}$ and is specifically designed to fill knowledge gaps in pediatric therapeutics, including a Food and Drug Administration label change. The PTN has established relationships with $\sim 200$ centers across the United States and therefore can quickly enroll participants. A disadvantage is that the PTN is focused on pharmacotherapies, which some of the proposed participants for this study might not be receiving. A second disadvantage is that PTN studies are generally short and not designed for long-term outcomes throughout childhood. However, collection of data on the use of medications known to be nephrotoxic could potentially be done within this network.

\section{The Vermont Oxford Network}

The Vermont Oxford Network is a nonprofit voluntary collaboration of health-care professionals working together as an interdisciplinary community to change the landscape of neonatal care. Founded in 1988, the Vermont Oxford Network now comprises nearly 1,000 centers around the globe that voluntarily submit data about the care and outcomes of highrisk newborn infants. The Vermont Oxford Network has coordinated programs for research, education, and quality improvement projects. The Vermont Oxford Network database maintains data on very-low-birth-weight infants and infants meeting other eligibility requirements.

\section{Canadian Neonatal Network}

The Canadian Neonatal Network is a group of Canadian researchers who collaborate on research issues relating to neonatal care. The Network was founded in 1995 and includes members from 30 hospitals and 17 universities across Canada. The Network maintains a standardized neonatal intensive care unit database and provides a unique opportunity for researchers to participate in collaborative projects on a national and international scale. Health-care professionals, health services researchers, and health administrators participate actively in clinical, epidemiologic, outcomes, health services, health policy, and informatics research aimed at improving efficacy and efficiency of neonatal care.

\section{Pediatrix}

Pediatrix Medical Group provides medical care for neonates in $>300$ neonatal intensive care unit across 33 states in Puerto Rico. Clinical care, medication administration, and laboratory data are documented in electronic medical records, which can then be queried. The clinical information system strategy provides a framework for research, education, and continuous quality improvement initiatives that allow clinicians to enhance outcomes nationwide. 
Table 3. Key elements necessary to conduct a study to understand the impact of neonatal acute kidney injury (AKI) on chronic kidney disease (CKD)

\begin{tabular}{|c|c|}
\hline 1 & $\begin{array}{l}\text { A prospective cohort study, tracking infants from their initial hospitalization to young adulthood, with serial evaluation of blood pressure } \\
\text { (with ABPM) and GFR (with formal GFR measurements) is optimal. }\end{array}$ \\
\hline 2 & $\begin{array}{l}\text { Formal renal follow-up of neonates (with manual blood pressure measurements, urine biomarkers, and eGFR equations) enrolled in } \\
\text { randomized controlled trials aimed at preventing or mitigating AKI is an opportunity to improve our understanding of interventions that could } \\
\text { ameliorate the short and long-term consequences of AKI. }\end{array}$ \\
\hline 3 & Cooperation between pediatric nephrologists and neonatologists is necessary. \\
\hline 4 & $\begin{array}{l}\text { A clear understanding of the neonatal course (as it relates to in-hospital kidney health) is necessary to make conclusions about the role that AKI } \\
\text { has in CKD development. }\end{array}$ \\
\hline 5 & $\begin{array}{l}\text { In addition to the impact of neonatal AKI, the contribution of intrauterine growth retardation, prematurity, and their interactions on CKD needs } \\
\text { to be elucidated. }\end{array}$ \\
\hline 6 & Educating neonatal clinicians and families about new concepts in neonatal AKI and the link between AKI and CKD is necessary. \\
\hline 7 & $\begin{array}{l}\text { Leveraging existing networks, creating a new neonatal collaborative and/or performing ancillary studies to existing neonatal studies will } \\
\text { facilitate infrastructure and allow achievement of the sample sizes needed to make meaningful conclusions. }\end{array}$ \\
\hline 8 & Effective recruitment and retention strategies will be critical for trial success. \\
\hline 9 & $\begin{array}{l}\text { Pilot studies are needed to determine methods to maximize recruitment and retention, assess feasibility of renal function reserve studies, } \\
\text { explore surrogate outcomes of CKD, and determine whether GFR estimation equations (such as the new Schwartz formula) are appropriate for } \\
\text { young children. }\end{array}$ \\
\hline
\end{tabular}

ABPM, ambulatory blood pressure monitoring; eGFR, estimated glomerular filtration rate.

\section{Pediatric Heart Network}

The Pediatric Heart Network was established in 2001 by the National Heart, Lung, and Blood Institute of the National Institutes of Health. It was created to help doctors and nurses design and carry out clinical research so that children with heart disease can receive high-quality, evidence-based care. As neonates who undergo cardiopulmonary bypass surgery are at high risk of AKI, and many Pediatric Heart Network studies support long-term outcomes, the Pediatric Heart Network could facilitate long-term studies of cardiopulmonary bypassassociated AKI in newborns.

\section{CONCLUSION}

The health and financial burden of CKD in children (and adults) who were born LBW or premature will continue to rise as smaller premature infants are living longer. At the National Institutes of Health-sponsored Neonatal AKI workshop in April 2013, nephrologists and neonatologists highlighted key elements necessary to conduct long-term studies of the sequelae of neonatal AKI (Table 3). These studies are greatly needed to provide evidence-based guidelines to the neonatal, pediatric, and nephrology communities. Research regarding short- and long-term consequences of neonatal AKI will inform cost-effective evaluations for CKD in vulnerable patients. More importantly, a more comprehensive understanding of the pathophysiology and epidemiology of AKI will lead to the design and implementation of adequately powered intervention studies to mitigate the progression to $\mathrm{CKD}$ in this very vulnerable population.

\section{ACKNOWLEDGMENTS}

We thank Abhik Das, Ahamad El Samra, Christine Hsu, Nicholas Larkins, Cherry Mammen, David Myers, Mary Revenis, Alyssa Riley, Subrata Sarkar, Marta Suarez-Rivera, Johannes Van Den Anker, Andrea Weintraub, Timothy Bunchman, Robert Chevalier, Loai Eid, Mamta Fuloria, James Green- berg, Karen Hendricks-Munoz, Frederick Kaskel, Michael Kuzniewicz, Jennifer McGuirl, Robert Pfister, George Schwartz, Phillip Brian Smith, Natalie Uy, and Panitan Yossuck for their participation in the workshop breakout sessions.

While NICHD staff had input into the meeting and manuscript drafting, the comments and views of the authors do not necessarily represent the views of the NICHD.

\section{STATEMENT OF FINANCIAL SUPPORT}

No financial assistance was received to support this study.

Disclosure: D.J.A. is on the speaker's bureau of the AKI Foundation. R.H. is an employee of the NIH-NICHD. Otherwise, none of the authors declare any potential conflicts of interest.

\section{REFERENCES}

1. Patel RM, Kandefer S, Walsh MC, et al.; Eunice Kennedy Shriver National Institute of Child Health and Human Development Neonatal Research Network. Causes and timing of death in extremely premature infants from 2000 through 2011. N Engl J Med 2015;372:331-40.

2. Mammen C, Al Abbas A, Skippen P, et al. Long-term risk of CKD in children surviving episodes of acute kidney injury in the intensive care unit: a prospective cohort study. Am J Kidney Dis 2012;59:523-30.

3. Askenazi DJ, Feig DI, Graham NM, Hui-Stickle S, Goldstein SL. 3-5 year longitudinal follow-up of pediatric patients after acute renal failure. Kidney Int 2006;69:184-9.

4. Coca SG, Yusuf B, Shlipak MG, Garg AX, Parikh CR. Long-term risk of mortality and other adverse outcomes after acute kidney injury: a systematic review and meta-analysis. Am J Kidney Dis 2009;53:961-73.

5. Chawla LS, Eggers PW, Star RA, Kimmel PL. Acute kidney injury and chronic kidney disease as interconnected syndromes. N Engl J Med 2014;371:58-66.

6. Basile DP, Yoder MC. Renal endothelial dysfunction in acute kidney ischemia reperfusion injury. Cardiovasc Hematol Disord Drug Targets 2014;14:3-14.

7. Sharkovska Y, Kalk P, von Websky K, et al. Renoprotective effects of combined endothelin-converting enzyme/neutral endopeptidase inhibitor SLV338 in acute and chronic experimental renal damage. Clin Lab 2011;57:507-15.

8. Basile DP, Friedrich JL, Spahic J, et al. Impaired endothelial proliferation and mesenchymal transition contribute to vascular rarefaction following acute kidney injury. Am J Physiol Renal Physiol 2011;300:F721-33. 


\section{Special Article | Askenazietal.}

9. Chikkannaiah P, Roy M, Kangle R, Patil PV. Glomerulogenesis: can it predict the gestational age? A study of 176 fetuses. Indian J Pathol Microbiol 2012;55:303-7.

10. Abrahamson DR. Glomerulogenesis in the developing kidney. Semin Nephrol 1991;11:375-89.

11. Rodríguez MM, Gómez AH, Abitbol CL, Chandar JJ, Duara S, Zilleruelo GE. Histomorphometric analysis of postnatal glomerulogenesis in extremely preterm infants. Pediatr Dev Pathol 2004;7:17-25.

12. Figueroa $\mathrm{H}$, Lozano $\mathrm{M}$, Suazo $\mathrm{C}$, et al. Intrauterine growth restriction modifies the normal gene expression in kidney from rabbit fetuses. Early Hum Dev 2012;88:899-904.

13. Matsuoka OT, Shibao S, Leone CR. Blood pressure and kidney size in term newborns with intrauterine growth restriction. Sao Paulo Med J 2007;125:85-90.

14. Machado Júnior LC, Passini Júnior R, Rodrigues Machado Rosa I. Late prematurity: a systematic review. J Pediatr (Rio J) 2014;90:221-31.

15. White SL, Perkovic V, Cass A, et al. Is low birth weight an antecedent of $\mathrm{CKD}$ in later life? A systematic review of observational studies. Am J Kidney Dis 2009;54:248-61.

16. Greenbaum LA, Muñoz A, Schneider MF, et al. The association between abnormal birth history and growth in children with CKD. Clin J Am Soc Nephrol 2011;6:14-21.

17. Basile DP. Rarefaction of peritubular capillaries following ischemic acute renal failure: a potential factor predisposing to progressive nephropathy. Curr Opin Nephrol Hypertens 2004;13:1-7.

18. Viswanathan S, Manyam B, Azhibekov T, Mhanna MJ. Risk factors associated with acute kidney injury in extremely low birth weight (ELBW) infants. Pediatr Nephrol 2012;27:303-11.

19. Koralkar R, Ambalavanan N, Levitan EB, McGwin G, Goldstein S, Askenazi D. Acute kidney injury reduces survival in very low birth weight infants. Pediatr Res 2011;69:354-8.

20. Carmody JB, Swanson JR, Rhone ET, Charlton JR. Recognition and reporting of AKI in very low birth weight infants. Clin J Am Soc Nephrol 2014;9:2036-43.

21. Askenazi DJ, Ambalavanan N, Goldstein SL. Acute kidney injury in critically ill newborns: what do we know? What do we need to learn? Pediatr Nephrol 2009;24:265-74.

22. Morgan CJ, Zappitelli M, Robertson CM, et al.; Western Canadian Complex Pediatric Therapies Follow-Up Group. Risk factors for and outcomes of acute kidney injury in neonates undergoing complex cardiac surgery. J Pediatr 2013;162:120-7.e1.

23. Bennett KM, Bertram JF, Beeman SC, Gretz N. The emerging role of MRI in quantitative renal glomerular morphology. Am J Physiol Renal Physiol 2013;304:F1252-7.

24. De Serres SA, Varghese JC, Levin A. Biomarkers in native and transplant kidneys: opportunities to improve prediction of outcomes in chronic kidney disease. Curr Opin Nephrol Hypertens 2012;21:619-27.

25. Schanstra JP, Zürbig P, Alkhalaf A, et al. Diagnosis and prediction of CKD progression by assessment of urinary peptides. J Am Soc Nephrol 2015;26:1999-2010.
26. Rasooly RS, Akolkar B, Spain LM, Guill MH, Del Vecchio CT, Carroll LE. The National Institute of Diabetes and Digestive and Kidney Diseases Central Repositories: a valuable resource for nephrology research. Clin J Am Soc Nephrol 2015;10:710-5.

27. Bosch JP, Saccaggi A, Lauer A, Ronco C, Belledonne M, Glabman S. Renal functional reserve in humans. Effect of protein intake on glomerular filtration rate. Am J Med 1983;75:943-50.

28. Roth-Cline B GJ, Bright P, Lee CS, Nelson RM. Ethical considerations in conducting pediatric research. In: Seyberth HW, Rane A, Schwab M, eds. Pediatric Clinical Pharmacology. New York: Springer, 2011: 219-44.

29. Sammons H. Ethical issues of clinical trials in children: a European perspective. Arch Dis Child 2009;94:474-7.

30. Natarajan G, Pappas A, Shankaran S, et al. Outcomes of extremely low birth weight infants with bronchopulmonary dysplasia: impact of the physiologic definition. Early Hum Dev 2012;88:509-15.

31. Mwaniki MK, Atieno M, Lawn JE, Newton CR. Long-term neurodevelopmental outcomes after intrauterine and neonatal insults: a systematic review. Lancet 2012;379:445-52.

32. The fourth report on the diagnosis, evaluation, and treatment of high blood pressure in children and adolescents. Pediatrics 2004;114: 555-76.

33. Schwartz GJ, Muñoz A, Schneider MF, et al. New equations to estimate GFR in children with CKD. J Am Soc Nephrol 2009;20:629-37.

34. Askenazi DJ, Griffin R, McGwin G, Carlo W, Ambalavanan N. Acute kidney injury is independently associated with mortality in very low birthweight infants: a matched case-control analysis. Pediatr Nephrol 2009; 24:991-7.

35. Gadepalli SK, Selewski DT, Drongowski RA, Mychaliska GB. Acute kidney injury in congenital diaphragmatic hernia requiring extracorporeal life support: an insidious problem. J Pediatr Surg 2011;46:630-5.

36. Kaur S, Jain S, Saha A, et al. Evaluation of glomerular and tubular renal function in neonates with birth asphyxia. Ann Trop Paediatr 2011;31: 129-34.

37. Askenazi DJ, Koralkar R, Hundley HE, Montesanti A, Patil N, Ambalavanan N. Fluid overload and mortality are associated with acute kidney injury in sick near-term/term neonate. Pediatr Nephrol 2013; 28:661-6.

38. Alabbas A, Campbell A, Skippen P, Human D, Matsell D, Mammen C. Epidemiology of cardiac surgery-associated acute kidney injury in neonates: a retrospective study. Pediatr Nephrol 2013;28:1127-34.

39. Selewski DT, Jordan BK, Askenazi DJ, Dechert RE, Sarkar S. Acute kidney injury in asphyxiated newborns treated with therapeutic hypothermia. J Pediatr 2013;162:725-729.e1.

40. Zwiers AJ, de Wildt SN, Hop WC, et al. Acute kidney injury is a frequent complication in critically ill neonates receiving extracorporeal membrane oxygenation: a 14-year cohort study. Crit Care 2013;17:R151.

41. Rhone ET, Carmody JB, Swanson JR, Charlton JR. Nephrotoxic medication exposure in very low birth weight infants. J Matern Fetal Neonatal Med 2014;27:1485-90. 